\title{
Study of the Development of Calcite Crystals and Carbonation by ESEM and DTA
}

\author{
Eva Soukupová ${ }^{1}$, Vilém Neděla ${ }^{1}$ \\ 1. Environmental Electron Microscopy Group, Institute of Scientific Instruments of the Czech Academy \\ of Sciences, Brno, Czech Republic.
}

Study of the development of calcite crystals and the process of carbonation is of great importance for lime and cement based building materials [1]. During the carbonation process, calcium hydroxide reacts with carbon dioxide to form calcium carbonate $[3,4]$.

Lime A with a grain size of under $200 \mu \mathrm{m}$, lime B with a grain size of under $200 \mu \mathrm{m}$ which was mixed for 5 minutes after hydration, and lump lime $C$ with a grain size from $10 \mathrm{~mm}$ to $63 \mathrm{~mm}$ were used to prepare the lime putties. Samples A, B, and C were taken from the prepared lime putties and these samples were stored in a box with $70 \%$ humidity and $20 \%$ concentration of $\mathrm{CO}_{2}$ for 30,60 , and 90 days for the accelerated carbonation. The different development of the calcite crystals and the rate of carbonation were monitored by the high resolution environmental scanning electron microscope (HRESEM) QUANTA 650 FEG (with a beam energy of $10 \mathrm{keV}$, a water vapour pressure of $200 \mathrm{~Pa}$, and a GSED detector) and by the Thermal analyser NETSCH STA 2500. The samples were studied directly without sputtering.

Fig. 1 show the development of the calcite crystals after 30,60, and 90 days of storage in a box. The length of the side of the calcite crystals was measured. The regular crystals which grew separately were selected for the measurement. The images in Fig. 1 and graph A in Fig. 2 show the different development of the calcite crystals. The calcite crystals grow over time. The smallest calcite crystals were developed in the lime putty which was prepared from the lime with a grain size of under $200 \mu \mathrm{m}$ (A30 - A90); whereas the larger crystals originated in the lime putty which was prepared from the mixed lime with a grain size of under $200 \mu \mathrm{m}$ (B30-B90). The largest calcite crystals were found in lime putty which prepared from the lump lime $(\mathrm{C} 30-\mathrm{C} 90)$. The rate of carbonation is demonstrated in graph $\mathrm{B}$ in Fig. 2. The smaller grains in the lime A lead to the slowest carbonation. The sample $\mathrm{C}$, prepared from lump lime, carbonates very quickly. The sample B contained less calcium hydroxide and, actually, more calcium carbonate than the sample $A$ due to the process of activation by the mixing after hydration. The content of calcium hydroxide decreases and the content of calcium carbonate increases over time. The size of calcite crystals and the rate of carbonation are affected by the preparation method of the lime putties and the granulometry of lime. The mixing process leads to the easier dissolution of the quicklime grains, subsequently to the formation of larger crystals of calcium hydroxide and quickly carbonation. The authors consider a high potential in the micro-morphological characterization of the calcite crystals in their native state by the ESEM. All requests for poster presentations will be honored [4].

References:

[1] P López-Arce et al, Powder Technology 205 (2011), p. 263.

[2] K Elert et al, Studies in Conservation 47 (2002), p. 62.

[3] K Van Balen, Cement Concrete Research 35 (2005), p. 647.

[4] The MEYS CR (LO1212), its infrastructure by the MEYS CR and the EC (CZ.1.05/2.1.00/01.0017) and by the CAS (RVO:68081731). 

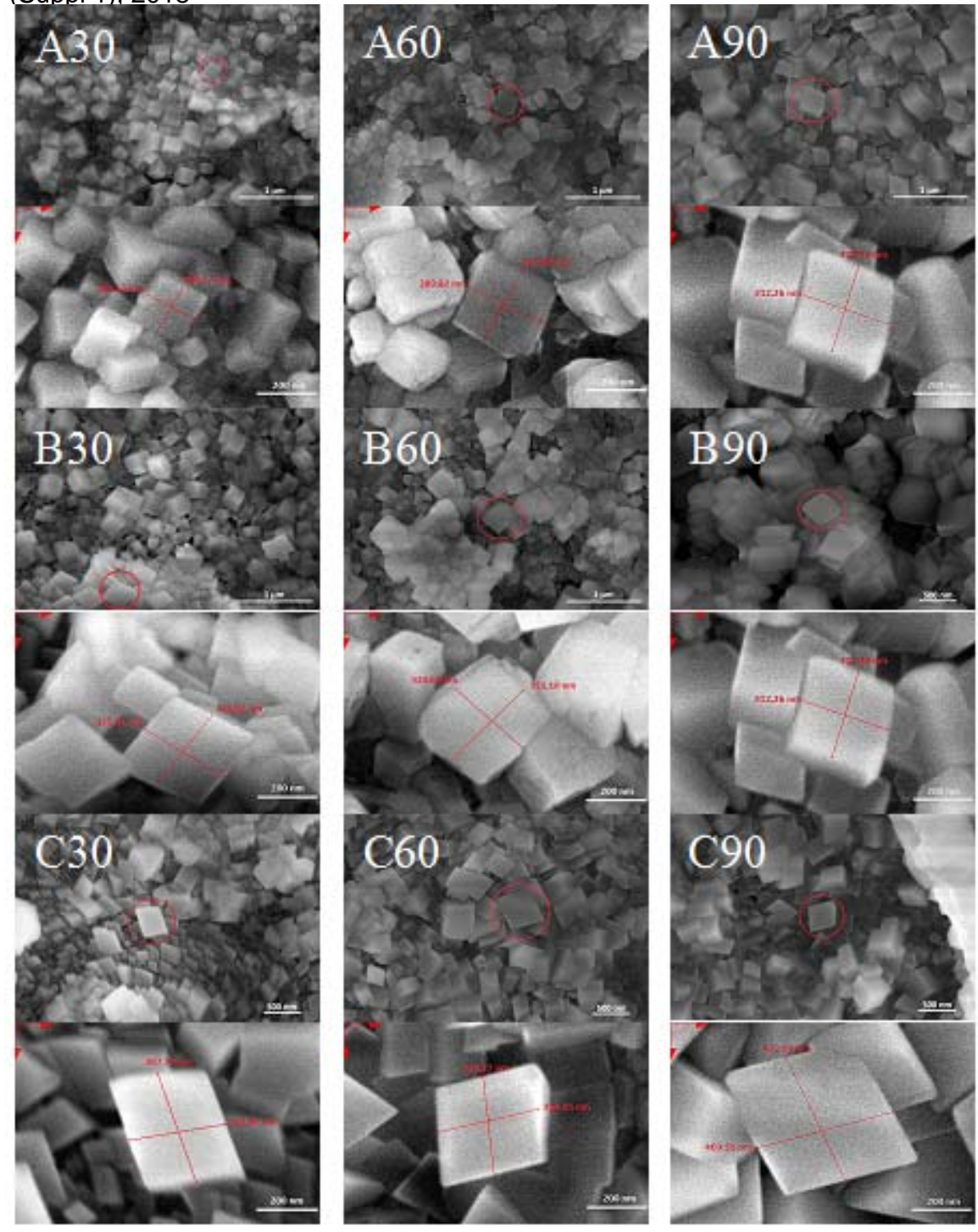

Figure 1. Microstructure of calcite crystals growth at the age of 30, 60, and 90 days.
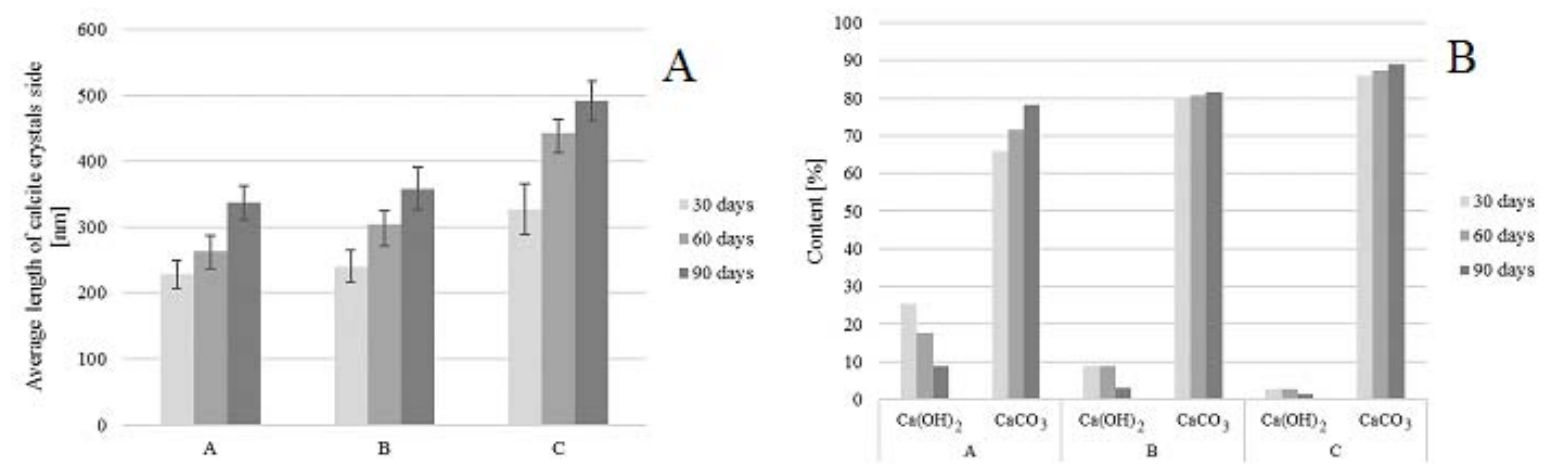

Figure 2. Average length of the calcite crystals side at the age of 30,60 , and 90 days (A). Content of $\mathrm{Ca}(\mathrm{OH})_{2}$ and $\mathrm{CaCO}_{3}$ at the age of 30,60 , and 90 days (B). 